\title{
A transposição das políticas de saúde mental no Brasil para a prática nos novos serviços
}

\author{
Juarez Pereira Furtado \\ Rosana Onocko Campos
}

A reestruturação da atenção em saúde mental no Brasil, preconizada pelo Movimento da Reforma Psiquiátrica se insere além da oferta de novos serviços ou da reestruturação de modelos assistenciais. Por se tratar de uma profunda alteração da resposta social à loucura, implica mudanças de ordem política, ideológica, ética e das concepções de clínica e reabilitação. No presente artigo, identificamos alguns impasses advindos da inserção do Movimento da Reforma Psiquiátrica nas políticas dos governos estaduais e do federal, abordamos questões originadas da transposição das diretrizes desta última para o plano operacional nos serviços e finalmente discutimos o papel estratégico da gestão destes últimos na tradução das diretrizes gerais em práticas assistenciais qualificadas.

Palavras-chave: Avaliação de serviços, gestão de serviços, políticas de saúde, reforma psiquiátrica 


\section{É possível enformar a reforma?}

Uma consulta aos dois principais dicionários da língua portuguesa nos fornecerá importantes subsídios para discutirmos as questões sob nosso foco no presente texto. De acordo com o Aurélio, existem várias acepções para "política", dentre elas a que afirma ser ela um "4. Conjunto de objetivos que enformam determinado programa de ação governamental e condicionam a sua execução" (Ferreira, 1986, p. 1.358).

Aqui, "política" é entendida como um conjunto de ações governamentais condicionadas e "enformadas" por certos objetivos, para a consecução de determinados fins. Podemos localizar aí importante questão a ser considerada: a transformação de novas iniciativas em saúde mental, da reforma psiquiátrica, numa política de governo ou "políticas de saúde mental".

Para considerarmos essa questão, devemos relembrar que o Movimento da Reforma Psiquiátrica no Brasil surge no contexto das lutas pela redemocratização do país, a partir do Movimento dos Trabalhadores de Saúde Mental (MTSM), no final dos anos 1970, que dará origem mais tarde ao Movimento da Luta Antimanicomial.

Oscilando, nos seus primórdios, entre reivindicações de qualificação da assistência psiquiátrica e outras de ordem coorporativa (Amarante, 2001), o MTSM ampliará paulatinamente o seu escopo, incluindo em sua trajetória perspectivas de ordem social, econômica e política, incorporando outros setores da população, como usuários e familiares (Yasui, 1999), estabelecendo o campo político e ideológico como seus lócus privilegiados.

Ou seja, o MTSM incorporará, além da necessidade de qualificação da assistência psiquiátrica, uma dimensão maior em seu discurso, representada pela transformação das relações sociais e a revisão das formas de segregação presentes na sociedade. (Essa luta contra a exclusão é bem ilustrada pela asserção segundo a qual "a reforma sempre buscou o reencontro da sociedade consigo mesma”.) 
Um dos pilares do Movimento de Reforma Psiquiátrica no Brasil será a luta pela desinstitucionalização, tanto em senso estrito como em outros sentidos gradativamente ampliados. Isso significa que o movimento buscará a superação das condições dos muitos internos cronificados em hospitais públicos e conveniados, mas também a transformação dos modelos assistenciais, dos paradigmas e das ações corporativas centradas no manicômio e suas práticas.

A superação da situação dos internos e da internação como única resposta à doença e ao doente mental torna-se a principal bandeira do Movimento da Reforma até meados dos anos 1990, quando a preocupação em expandir a rede substitutiva no Sistema Único de Saúde (SUS) começa a ganhar corpo e vem somar-se aos esforços da desinstitucionalização. Afinal, não basta fechar o manicômio, é preciso haver pessoas e equipamentos sociais e de saúde para acolher e acompanhar os egressos de longas internações bem como os novos pacientes na comunidade.

A crítica aos manicômios e ao Movimento de Desinstitucionalização - por um lado - e a necessidade de prover um sistema de saúde mental inserido no SUS, alternativo ao modelo hospitalocêntrico, garantindo assim uma nova resposta ao portador de transtornos mentais - por outro - estabelecem pontos de contato entre as reformas psiquiátrica e sanitária. No entanto, essa aproximação não será simples, nem automática.

Ainda que os dois movimentos tenham pontos de origem comuns nasceram de corporações intelectuais e das perspectivas das classes trabalhadoras, estabeleceram alianças com diferentes segmentos da sociedade, participaram de lutas sociais ligadas às ações transformadoras da sociedade (Yasui, 1999) -, as reformas sanitária e psiquiátrica apresentaram, no entanto, sensíveis diferenças.

Enquanto o Movimento da Reforma Sanitária optou pela ocupação de postos estratégicos no aparelho estatal, o da Reforma Psiquiátrica priorizou o estabelecimento de articulações intersetoriais, a inclusão de familiares e usuários e toda uma sorte de fóruns, associações, manifestações públicas, que em muito contribuíram para que a iniciativa viesse a extrapolar o setor de saúde, contando com a decisiva adesão de outros segmentos da sociedade.

Para Amarante (2001), a Primeira Conferência Nacional de Saúde Mental, em 1987, marca o distanciamento da reforma psiquiátrica do sanitarismo em decorrência da opção prioritária pela estratégia da desinstitucionalização e da desconstrução/invenção. Para o autor (ibid.), esse distanciamento estaria calcado em algumas diferenças essenciais:

- os planos sanitaristas criam mecanismos de referência/contra-referência, controle epidemiológico, protocolos de atendimento, mas sem conseguir escutar as diversas singularidades a respeito do sujeito que sofre; 
- enquanto os sanitaristas trabalham com a idéia de que é preciso mudar a Política Nacional de Saúde Mental para que uma pessoa seja bem atendida, os militantes da reforma psiquiátrica identificam na desinstitucionalização/desconstrução do cotidiano das instituições e em novas formas de lidar com a loucura a principal via de transformação de um status quo inaceitável.

O estreito compromisso com a desinstitucionalização de idéias, de práticas e de pacientes poderia explicar uma certa resistência do Movimento da Reforma Psiquiátrica - ao contrário do da Reforma Sanitária - em ingressar nas instâncias oficiais e de poder público, já que a não-institucionalização era uma condição que se buscava preservar (Amarante, 2001).

Mas o distanciamento das duas reformas será sempre relativo, uma vez que ambas inevitavelmente estarão interligadas pelo SUS. Vários fatores catalisarão essa complexa e cambiante aproximação. Dentre eles, destacamos as experiências bem-sucedidas de alguns municípios na superação do manicômio e implementação de uma rede substitutiva, como foi o caso da experiência santista.

O sucesso de experiências inovadoras como as ocorridas em Santos, a partir de 1989, com o fechamento da Casa de Saúde Anchieta e a implementação de uma ampla rede territorial de serviços de saúde mental, em funcionamento $24 \mathrm{~h} /$ dia, sete dias por semana vai se tornar emblema da possibilidade de se realizar profundas mudanças na atenção em saúde mental dentro da rede SUS.

Além disso, houve uma expansão gradual de forças progressistas em outros governos municipais, comprometidas com a reforma psiquiátrica e com a construção do SUS, que desenvolveram experiências espelhadas na trajetória santista e também na criação de outros novos dispositivos (Venâncio et al., 1997).

Outro fator que veio acelerar a aproximação entre as duas reformas foi a situação dos quase cem mil leitos psiquiátricos existentes no início da década de 1990, compostos em sua maioria de pacientes cronificados, e que requeria soluções em escalas compatíveis com o tamanho do problema.

A reaproximação entre as reformas citadas concretiza-se com a transformação em leis federais, estaduais e municipais de propostas originadas nas Conferências Nacionais de Saúde Mental e na criação da Comissão Nacional de Saúde Mental (Costa-Rosa et al., 2001), culminado com a promulgação da lei 10.216/2001, da Reforma Psiquiátrica Brasileira. Há ainda várias portarias ministeriais que viabilizaram a organização e o financiamento dos chamados Centros de Atenção Psicossocial (Caps), Serviços Residenciais Terapêuticos (moradias) e oficinas protegidas (Brasil, 2004).

Assim sendo, a reforma psiquiátrica como política do governo federal, do SUS e de muitos estados e municípios ganha um status até então inédito: seus atores e suas reivindicações são incluídos nas instâncias de decisão do SUS, por 
meio da mesma estratégia do movimento sanitário: institucionalizando-se como política oficial (Costa-Rosa et al., 2001).

O que vimos expondo nos leva à primeira questão aqui proposta: seria possível oficializar a reforma psiquiátrica, mantendo ao mesmo tempo sua potência e capacidade de instaurar o novo, de colocar em questão instituições e paradigmas?

Ou visto por outro prisma: é possível reduzir ou atenuar os inevitáveis impactos ao Movimento da Reforma Psiquiátrica - provenientes de sua nova condição de política de governo - à sua capacidade instituinte? Como já afirmado por Passos, ${ }^{1}$ o que interessa no movimento de reforma psiquiátrica é justamente... o movimento!

E mais especificamente, segundo o enfoque proposto neste artigo: como trans-portar e trans-formar os novos referenciais para os serviços (novos ou não), de modo a garantir a oferta e realização de práticas assistenciais essencialmente não segregadoras, não alienantes e inclusivas? Considerando que tais diretrizes materializam-se e atualizam-se no contato entre profissional e paciente, até que ponto esse encontro estaria imbuído das novas concepções?

\section{É possível instaurar posturas?}

Conforme já discutido por Nicácio (2002), a reforma psiquiátrica representa muito mais do que a implementação de novos serviços em saúde mental. No limite, trata-se de uma nova relação com a loucura e suas formas de abordagem, devendo instaurar uma nova resposta social ao adoecimento e ao doente mental.

Para garantirmos que a reforma psiquiátrica avance para além da simples implementação de novos (e mais) serviços, precisamos ter um quadro de profissionais imbuídos de uma postura profissional profundamente distinta do modelo anterior. Sobretudo se considerado o fato de que as novas modalidades de atenção em saúde mental não se resumem a novas técnicas de tratamento, mas constituem outra política, uma ética de inclusão - um novo paradigma, no sentido kuhniano (Kuhn, 1991) do termo.

Tais premissas nos levam a uma questão cuja solução é crucial: como instaurar uma nova postura, uma outra ética de cuidados, uma nova forma de lidar com o doente mental entre os milhares de trabalhadores de saúde mental do país? (Estejam estes em "novos" ou "velhos" serviços.)

Naturalmente, os profissionais que militaram pelas mudanças, que puderam experienciar transformações institucionais e/ou participaram das discussões

1. Passos, E. anotações de aula. 
políticas do setor, provavelmente conseguem traduzir os princípios da reforma para as práticas cotidianas.

Mas o que fazer com a outra grande maioria representada pelos que não tiveram oportunidade de aprender com o antiexemplo de alguns manicômios ou não tiveram contato com a militância e os movimentos pró-reforma? Além disso, devemos considerar que as instituições de formação assimilaram muito pouco das discussões trazidas pela reforma e vêm oferecendo ainda tímidas contribuições em termos de avaliação e propostas para o seus desenvolvimento.

A tendência inicial é repetir o referencial aprendido anteriormente e repetido durante anos. Ressaltamos que o risco da burocratização e alienação do objeto e objetivo do trabalho é maior nos trabalhadores da saúde mental que nos trabalhadores da saúde em geral. Isso porque a convivência com a loucura e seus desdobramentos não é algo simples e fácil - razão pela qual, justamente, as sociedades criaram todas as formas de defesa que hoje tentamos superar.

A formação de profissionais em serviços é uma alternativa importante e necessária. No entanto, nossa prática cotidiana tem evidenciado que a "formação permanente" ainda que imprescindível é insuficiente na geração de novas posturas éticas, de um novo posicionamento e abertura diante daquele que padece de grande sofrimento psíquico.

E aqui tocamos em um dos dilemas da reforma psiquiátrica: a decodificação cotidiana dos princípios políticos, ideológicos e éticos da reforma psiquiátrica pelos atores que a realizam na ponta, ou seja, no contato direto com o usuário. $\mathrm{O}$ que fazer para que os novos serviços e seus trabalhadores efetivem realmente novas políticas, novas respostas, novas posturas entre os usuários?

\section{Para além da saúde mental ortopédica e da clínica alienada}

Na segunda consulta aos dicionários, em relação ao título deste artigo, vimos que "saúde mental" está sob a rubrica "psiquiatria", definida como "Estado caracterizado pelo desenvolvimento equilibrado da personalidade de um indivíduo, boa adaptação ao meio social e boa tolerância aos desafios da existência individual e social" (Houaiss, 2002).

Talvez resida aí um dos maiores riscos da reforma: desobrigar a sociedade de repensar a relação estabelecida com a doença mental ao longo dos últimos dois séculos, ao privilegiar a adaptação do doente mental ao meio - ainda que isso venha a custar o próprio apagamento do sujeito, no sentido psicanalítico do termo. 
Como já afirmado por Saraceno (1999), a verdadeira reabilitação psicossocial passa por adaptações também do ambiente físico e social daqueles que apresentam algum grau de desvantagem ou desabilidade, devendo operar sobre o que o autor chama de "efeito contexto". Ou seja, as ações reformadoras em psiquiatria, se pretendem instaurar uma nova resposta social à loucura, deverão necessariamente aumentar a permeabilidade da comunidade ao convívio - com e apesar das diferenças.

Assim sendo, uma concepção de saúde mental "ortopédica", como apresentada na definição anterior deve ser abandonada em favor de um referencial que realmente represente um novo paradigma do cuidar. Precisamos de uma noção de saúde mental que considere a confluência da “... Psiquiatria, da Psicanálise e da Psicologia, articulados a conhecimentos das Ciências Sociais, no movimento de configuração de um campo de saber de natureza interdisciplinar" (Giordano Jr. \& Pereira, 2000).

Confluência de vários saberes e propiciador de uma certa relativização de poderes entre categorias profissionais, o recente e complexo campo da saúde mental possui limites imprecisos e indefinições - o que o torna exatamente por isso bastante propício às experimentações e produção de novas práticas.

Não por acaso, a saúde mental vem sendo um espaço, por excelência, para o desenvolvimento de novas formas de cuidado, novas formas de colaboração interprofissional, e, sobretudo, geradora de novos modelos de atenção e funcionamento institucional (Onocko Campos, 2003; Campos, 2000; Furtado, 2001).

Entretanto, o campo da saúde mental apresenta polarizações importantes, sendo a questão da clínica versus outras formas de abordagem bastante emblemática das diferenças dos debates presentes em seu interior. Como afirmado por Tenório (2001), "Sabemos que o movimento da reforma compreende, grosso modo, duas posições sobre a natureza da transformação almejada, uma que enfatiza a dimensão política e social, propondo a superação da clínica, outra que considera haver no fato da loucura uma especificidade que só a clínica é capaz de acolher de forma positiva" (p. 53).

Do nosso ponto de vista, o dilema entre clínica e saúde mental precisa ser mais considerado e novas vias de interação estabelecidas. Essa polarização talvez tenha como pano de fundo o que Costa (1996) chamou respectivamente de ética da interlocução e ética da ação social, em seu instigante texto "As éticas da psiquiatria".

Segundo o autor (ibid.), a ética da interlocução não define o sujeito como privado de vontade ou razão, mas como portador de uma outra vontade e de uma outra razão, baseando-se fundamentalmente na ética da moral privada. Para a ética da interlocução, sujeito e agente são definidos no vocabulário psicológico. 
Já a ética da ação social coloca em questão o sujeito do direito, sendo o ideal da assistência aquele que faz equivaler virtudes políticas a virtudes terapêuticas. Aqui, sujeito e agente da assistência definem-se como pares, normalmente como cidadãos. A ênfase no estatuto de cidadão é prioritária.

Para Costa (ibid.), as duas éticas são passíveis de crítica. A ética da interlocução, ao dar ênfase à individualidade, levaria à moral de fato, sem nenhuma transcendência, perdendo de vista tudo o que não seja o indivíduo [questão abordada criticamente por Laurent (1999) a propósito de seu artigo "O analista cidadão"]. Já a ética da ação social acaba por desconsiderar aspectos intrínsecos àquele que sofre e que estão além (ou aquém) das conseqüências sociais de seu padecer.

A clínica, por um lado, diz respeito ao caso tomado em sua singularidade. A saúde mental, por outro, diz respeito às ações políticas e eticamente orientadas, só que referida a uma singularidade não individual, à singularidade de um certo grupo. Melhor dizendo, a saúde mental diz respeito às especificidades de um grupo social portador de um traço comum (no caso, a "loucura" e a exclusão social).

A clínica e a saúde mental complementam-se ao nos permitir distinguir e operar simultaneamente sobre a exclusão que resulta de processos subjetivos e também sobre procedimentos excludentes que passam pelo contexto do paciente, como a família, a escola, e vão até o manicômio e outras formas de intolerância social (Carvalho, 1999). Essa convergência entre a clínica e a saúde mental viria ao encontro do que Campos (1995) chama de "clínica ampliada".

Ou seja, a clínica vem nos dizer que existe um sujeito no indivíduo que está no mundo. A saúde mental vem nos lembrar das determinações sociais, políticas e ideológicas que o envolvem nesse mesmo mundo. Ambas devem ser consideradas no âmbito do tratamento de nossos usuários, sem antagonismos nem sobreposições. Como afirmado por Seidinger (2002), “... a clínica psicanalítica, regida pela ética do bem dizer convive na instituição alinhando-se com a prática da saúde mental, regida pela ética do bem-estar de forma a não praticar a segregação (praticada, por exemplo, pela ciência, pelo nominalismo...). Ambas incluem o sujeito no discurso e no mundo" (p. 9).

Considerar o sujeito do direito e o sujeito do inconsciente é nosso grande desafio. No entanto, entre uma saúde mental e uma reabilitação psicossocial ortopédicas ou uma clínica alienada e pouco cidadã - por um lado - e uma clínica ampliada e uma reabilitação realmente inclusiva e condizente com a diferença por outro - existem muitos caminhos possíveis.

Qual deveria ser o modelo de funcionamento dos serviços comprometidos com a reforma psiquiátrica, de modo que considerasse e coordenasse a complexidade oriunda das diretrizes de mudança, das peculiaridades de cada 
trabalhador e da polissêmica e multifacetada demanda que ali acorre na presença de cada usuário?

\section{Uma tradução possível por meio da gestão transversalizada}

Sabemos que não há um único caminho possível ou um só esforço capaz de fazer frente à extensa tarefa de transpor os princípios da reforma psiquiátrica para o plano das práticas. A educação permanente dos trabalhadores, a avaliação sistemática das novas práticas, a inclusão da perspectiva dos usuários no processo (Soalheiro, 2003; Vasconcelos, 2003), dentre outras, são vias importantes e necessárias ao estabelecimento dos novos referenciais na prática cotidiana de atenção em saúde mental.

Neste texto, no entanto, ressaltaremos um fator que consideramos relevante para a efetividade da reforma no plano dos serviços: a gestão dos equipamentos. Parece-nos que a gerência e as formas de gestão nos serviços podem contribuir de maneira significativa na decodificação de diretrizes gerais em práticas alinhadas ética e ideologicamente às premissas da reforma de que vimos tratando.

Como já afirmado, uma das maneiras de o SUS se exercer enquanto política de saúde é por meio de ações verticais, de diretrizes, portarias resoluções, programas e outros expedientes que representam a tentativa do Ministério da Saúde de fazer chegar suas políticas aos vários níveis.

No entanto, como interagir com essa verticalidade, que atravessa as diferentes instâncias que constituem o SUS: secretaria estadual, secretaria municipal, serviços de saúde? Do ponto de vista da gestão, acreditamos haver dois pólos de interações possíveis.

O primeiro seria o do aprofundamento da verticalidade iniciada no plano federal, isto é, as normas encontram modelos de gestão e operacionalização cujas ações se efetuam de maneira burocrática e descontextualizada: tudo se reduz aos índices a serem alcançados e às metas a serem cumpridas.

O outro pólo seria representado pelo encontro das diretrizes políticas (e suas normas) com modelos de gestão tendentes à horizontalização, que possibilitem e convoquem a maior participação dos profissionais de saúde e da população no gerenciamento das políticas de saúde ali realizadas. Nesse último caso, as diretrizes gerais serão compreendidas e adaptadas ao contexto, numa perspectiva de alargamento de suas possibilidades.

Quando o eixo vertical - das diretrizes e normativas da política de governo - encontra no eixo horizontal - nível das demais instâncias de execução das políticas de saúde - maior porosidade, maior capacidade de articulação, maior 
engajamento dos diferentes atores que constituem o campo da saúde, opera-se uma rotação do eixo que tende à transversalização.

Isso se traduziria no contato com a externalidade da instituição, do setor, do corporativismo profissional, da secretaria, do hospital, numa mudança de sentido, de atitude, para a construção de melhores condições de trabalho dos profissionais, de melhor atendimento aos usuários e de uma rede regionalizada que potencialize os recursos humanos e técnicos na atenção à saúde.

No caso dos Caps, serviços de caráter público, que carregam a encomenda social da inovação e do compromisso com a mudança cultural em relação ao imaginário social sobre a loucura, a necessidade de produzir um coletivo pouco engessado e pouco burocratizado está enfaticamente destacada.

No entanto, os Caps não deixam de ser serviços públicos de saúde, integrantes do SUS - sistema esse que vem institucionalizando sobremaneira e começa a dar sinais de burocratização, de perda de agilidade, de excessiva verticalidade. Como estar dentro da rede sem se enredar na armadilha do instituído?

Por um lado, os Caps compõem-se de uma estrutura alinhada aos princípios que norteiam os demais serviços de saúde pertencentes ao SUS: compõem-se de uma instituição própria, inserida na gestão pública, buscando garantir acesso, eqüidade, integralidade e resolutividade na atenção prestada.

Por outro lado, a subversão da lógica da hierarquização efetivada pelos Caps ao estruturarem-se como "equipamentos-síntese" (Nicácio, 1994), agregando os diferentes níveis de atenção em uma só unidade, e a inevitável e necessária consideração das repercussões subjetivas do atendimento a psicóticos nos trabalhadores desses serviços (Kirschbaum, 2000) fazem emergir relevantes questões e debates no âmbito da própria organização do SUS.

Desse modo, os novos aspectos organizacionais decorrentes da reforma psiquiátrica em geral e da emergência dos Caps em particular colocam em especial evidência as inter-relações entre subjetividade, processo de trabalho e gestão (Onocko Campos, 2001), cuja consideração vai requerer dispositivos específicos para a abordagem dos processos envolvidos.

Nesse caso, o Método Paidéia idealizado por Campos (2000) nos parece especialmente apropriado ao possibilitar uma forma de organização de serviços coerente com os princípios de inclusão, participação e horizontalização presentes na reforma psiquiátrica.

Além disso, o Método Paidéia ou Método da Roda, cuja elaboração tem por base a leitura crítica de textos no campo da política, do planejamento, da análise institucional e da educação permanente, está fundamentado na consideração de que a gestão necessariamente produz efeitos nos âmbitos administrativo e financeiro, político, pedagógico e da subjetividade dos sujeitos envolvidos - o 
que é compatível com os vários aspectos que se pressupõe sejam considerados no processo de mudança em saúde mental.

Para esse método, a gestão como elemento isolado seria uma abstração, uma vez que, efetivamente, existe sempre algum grau de co-gestão, pois muitos e diferentes atores geralmente estão implicados no processo, com algum poder de intervenção.

Por conceber a existência de relações dialéticas entre determinismos de diversas ordens e a capacidade de reação dos sujeitos, o Método Paidéia nos parece pertinente para a consideração de toda a complexidade envolvida na condução de serviços que se propõem a uma nova relação e resposta à loucura: serviços compostos por grupos-sujeitos que em diferentes graus de co-gestão são capazes de negociar normas e diretrizes, gestão e subjetividade, razão e loucura, segundo os diferentes contextos.

Devemos alertar que, no plano das práticas cotidianas, a gestão participativa não se resume a reuniões de equipe. É preciso estar sempre atento aos pontos cegos, ao recalcado nas reuniões e no dia-a-dia, àquilo do qual nunca se fala.

Um bom gerente também ficará atento aos silêncios que as questões de poder impõem à equipe. Quanta voz tem os auxiliares? Quem participa da construção do caso clínico? Como tem sido a trajetória dos usuários num dado serviço?

Enfim, a dimensão da gestão não deve ser subestimada no profundo e intenso processo de mudanças proposto pela Reforma Psiquiátrica. Afinal, não podemos nos esquecer de que a complexidade é característica desse percurso, do qual o inusitado, o particular e o inesperado poderão sempre se fazer presentes, requerendo da gestão (ou da co-gestão) especial competência e envolvimento.

Como dissemos em outro momento, podemos pensar a gestão de iniciativas da reforma psiquiátrica como “... permanente produtora de processos de institucionalização. Trabalhando sempre numa transversal tensionada entre o instituído e o instituinte, entre a ordem que sustenta a operatória de outros processos produtivos, e a desordem dos processos criativos e de mudança" (Onocko Campos, 2003, p. 147).

\section{Referências}

Amarante, Paulo. Loucos pela vida: a trajetória da reforma psiquiátrica no Brasil. Rio de Janeiro: Fiocruz, 2001.

Brasil, Ministério da Saúde. Legislação em saúde mental: 1990-2004, 2004.

Campos, Gastão Wagner Souza. Um método para análise e co-gestão de coletivos. São Paulo: Hucitec, 2000. 
Considerações sobre a arte e ciência da mudança: a revolução das coisas e a reforma das pessoas. In: Cecilıo, Luiz Oliveira. Inventando a mudança em saúde. São Paulo: Hucitec, 1995.

Carvalho, Frederico Feu. Teoria e clínica no Cersam. Metipolá, v.1, n. 1, p. 39-41, 1999. Costa, Jurandir Freire. As éticas da psiquiatria. In: Figueiredo, Ana Cristina e Silva Filho, João Ferreira (orgs.). Ética e saúde mental. Rio de Janeiro: Topbooks, 1996.

Costa-Rosa, Abílio et al. As conferências nacionais de Saúde Mental e as premissas do modo psicossocial. Saúde em Debate, Rio de Janeiro, v. 25, n. 58, p. 12-25, maioago/2001.

Ferreira, Aurélio Buarque de Holanda. Novo Dicionário da Língua Portuguesa. 2. ed. São Paulo: Nova Fronteira, 1986.

Furtado, Juarez Pereira. Responsabilização e vínculo no tratamento de pacientes cronificados. In: HARARI, Angelina \& VALENTINI, Willians (orgs.). A reforma psiquiátrica no cotidiano. São Paulo: Hucitec, 2001.

Giordano Jr., Sylvio \& Pereira, Lygia Maria de França Pereira. Saúde mental. In: Schraiber, Lílian Blima; Nemes, Maria Inês Baptistella; Mendes-Gonçalves, Ricardo Bruno (orgs.). Saúde do adulto: programas e ações na unidade básica. São Paulo: Hucitec, 2000.

Houaiss, Antônio. Dicionário de Língua Portuguesa, <http://noticias.uol.com.br/ educacao> Acesso em: 21 setembro 2004.

Kirschbaum, Débora Isane Ratner. O trabalho de enfermagem e o cuidado em saúde mental: novos rumos? Cadernos do IPUB, v. 6, n. 19, p. 15-36, 2000.

Kunn, Thomas. A estrutura das revoluções científicas. São Paulo: Perspectiva, 1991.

Laurent, Eric. O analista cidadão. Curinga, EBP-MG, n. 13, set/99.

NicÁcio, Maria Fernanda. Utopia da realidade: contribuições da desinstitucionalização para a invenção de serviços de saúde mental. 2002. 213 p. Tese (doutorado em Medicina Preventiva e Social). Universidade de Campinas.

O processo de transformação em saúde mental em Santos: desconstrução de saberes, instituições e cultura. 1994. 155 p. Dissertação (mestrado em Ciências Sociais). Pontifícia Universidade Católica de São Paulo.

Onocko CAmpos, Rosana. Clínica: a palavra negada - sobre as práticas clínicas nos serviços substitutivos de saúde mental. Saúde em Debate, Rio de Janeiro, v. 25, n. 58, p. 98-111, maio-ago/2001.

A gestão: espaço de intervenção, análise e especificidades técnicas. In: CAMPos, Gastão Wagner Souza (org.). Saúde Paidéia. São Paulo: Hucitec, 2003.

SARACENo, Benedetto. Libertando identidades: da reabilitação psicossocial à cidadania possível. Rio de Janeiro: TeCorá, 1999. 
SeIdinger, F.M. O "bem dizer" e o "bem-estar" - as éticas da psicanálise e da saúde mental podem conviver na instituição?. 2002. 9 p., Mimeo.

SoAlheiro, Nina Isabel. Da experiência subjetiva à prática política: a visão do usuário sobre si, sua condição, seus direitos. 2003. 189 p. Tese (doutorado em Saúde Pública). Escola Nacional de Saúde Pública.

TenóRIo, Fernando. A psicanálise e a clínica da reforma psiquiátrica. Rio de Janeiro: Rios Ambiciosos, 2001.

YAsui, Sílvio. A construção da reforma psiquiátrica e o seu contexto histórico. 1999. 192 p. Dissertação (mestrado em Ciências e Letras). Universidade Estadual Paulista, Campus de Assis.

VAsconcelos, Eduardo Mourão. O poder que brota da dor e da opressão: empowerment, sua história, teorias e estratégias. Rio de Janeiro: Paulus, 2003.

\section{Resumos}

La reestructuración de la atención en salud mental en Brasil preconizada por el Movimiento de Reforma Psiquiátrica se ejerce más allá de la oferta de nuevos servicios o de la reestructuración de modelos asistenciales. Tratándose de una profunda alteración de la respuesta social a la locura, implica en mudanzas de orden política, ideológica, ética y de las concepciones de clínica y de rehabilitación. En el presente artículo, identificamos algunos obstáculos advenidos de la inserción del Movimiento de Reforma Psiquiátrica en las políticas de los gobiernos federal y provincial; abordamos cuestiones originadas en la transposición de las directrices de esta última para el plano operacional en los servicios y finalmente discutimos el papel estratégico de la gestión de estos últimos en la traducción de las directrices generales en prácticas asistenciales cualificadas

Palabras claves: Evaluación de servicios de salud, gestión en salud, políticas de salud, reforma psiquiátrica

La réorganisation des soins dans le domaine de la santé mentale au Brésil préconisée par le Mouvement de Réforme Psychiatrique va au delà de l'offre de nouveaux services ou de la réorganisation des modèles d'assistance. En visant un changement profond de la réponse sociale à la folie, la réforme suggère des changements d'ordre politique, idéologique et éthique, et l'évolution des conceptions de la clinique et de la réhabilitation. Dans cet article, nous identifions certaines impasses résultant de l'insertion du Mouvement de Réforme psychiatrique dans la politique des gouvernements fédéraux et régionaux; nous abordons des problématiques découlant de la transposition des orientations générales proposées par le Mouvement 
au plan opérationnel dans les services; et finalement, nous discutons le rôle stratégique de la gestion de ces services dans la traduction des directrices de la réforme en des pratiques d'assistance qualifiées.

Mots clés: Évaluation des services, gestion ds services, politique sanitaire, réforme psychiatrique

The reorganization of mental health care in Brazil promoted by the Movement for Psychiatric Reform goes beyond the offer of new services and the reorganization of models of care. It concerns deep changes in social response to madness and implies changes in political, ideological, and ethical issues as well as in clinical and rehabilitation concepts. In this article we identify impasses related to the absorption of the Movement for Psychiatric Reform by federal and state government policies. We also approach issues resulting from such policies as they are put into practice in the services rendered. Finally, we discuss the strategic role of the management of these services in the application of the governments' general guidelines for quality care.

Key words: Health care evaluation, health care management, health policies, psychiatric reform 